\title{
Feeling Lucky: The Serendipitous Nature of Field Education
}

\author{
Kathryn Hay ${ }^{1}\left(\right.$ ) Jane Maidment ${ }^{2} \cdot$ Neil Ballantyne $^{3} \cdot$ Liz Beddoe $^{4} \cdot$ Shayne Walker $^{5}$
}

Published online: 11 October 2018

(c) Springer Science+Business Media, LLC, part of Springer Nature 2018

\begin{abstract}
Field education and the supervision that occurs during this process cements learning and enhances preparedness for a career in social work. Graduate readiness for social work practice is however a contested subject in New Zealand with recent criticism focusing on the adequacy of social work education. This paper reports on findings from focus groups with 27 faculty members and 35 students from eight Schools of Social Work in New Zealand which explored aspects of the taught and learned curriculum. Overall, students and faculty revealed some dissatisfaction with the taught curriculum on supervision that occurs on campus prior to the placement experience. Many students reported irregularity of placement supervision and associated quality supervision with being lucky. We propose a series of recommendations to address these concerns, emphasizing that students should be able to consistently access effective placement supervision rather than consider this a matter of luck.
\end{abstract}

Keywords Supervision $\cdot$ Luck $\cdot$ Field instructor $\cdot$ New Zealand $\cdot$ Availability of field education

Every year in New Zealand approximately 800 students are eligible to graduate with either a Bachelors or Masters Applied degree in social work. Despite these numbers, little is known about the quality of program delivery or the satisfaction graduates have with their professional education. Stakeholder views on social work graduate readiness to practise remain anecdotal with minimal research conducted on workforce retention and development in New Zealand. Notwithstanding this lack of empirical evidence, public figures such as the Minister for Social Development (Bennett 2014), and the Commissioner for Children in New Zealand (Radio NZ 2015), have been forthright with their criticism of social work practitioner competence to intervene effectively in cases of child protection and family violence. In response to these criticisms a 3 year mixed methods research project focused on gathering empirical evidence about social work education was initiated in 2016. The project aims to develop

Kathryn Hay

k.s.hay@ massey.ac.nz

1 School of Social Work, Massey University, Palmerston North, New Zealand

2 University of Canterbury, Christchurch, New Zealand

3 Open Polytechnic, Wellington, New Zealand

4 University of Auckland, Auckland, New Zealand

5 Otago University, Dunedin, New Zealand a professional capabilities framework for newly qualified, advanced and expert social workers in New Zealand. This article discusses the findings from focus groups with social work faculty members and students related to the field placement component of social work education with an emphasis on student supervision.

\section{Background}

In New Zealand, all social work students undertake a minimum of 120 days of field placement in two different organizational settings, receiving a minimum of $1 \mathrm{~h}$ of formal supervision per week (SWRB 2017). Prior to the placement, students receive classroom teaching at the higher educational institute about styles of supervision, their role as a supervisee and the requirements and expectations associated with placement supervision. Registration of social workers is not yet mandatory in New Zealand but the Social Workers Registration Board (SWRB), the regulatory government entity responsible for recognition of social work programs, stipulates that all students must receive supervision during placement from a registered supervisor. This requirement has placed considerable onus on degree providers to find placements in organizations that have field instructors who meet this criteria or alternatively pay for an external field instructor to provide the regular supervision. External field 
instructors usually provide weekly or fortnightly supervision away from the placement organization and they do not interact with the student's clients during the placement. Observation of the student during the placement is generally undertaken by the person responsible for the student in the organization (not social work registered) not the external field instructor. This situation is especially challenging in an environment where registration is not mandatory and placement agencies do not necessarily employ registered social workers. There is no research to suggest that registered social workers provide better supervision to students than non-registered social workers.

Field instructors in New Zealand are not required to have a graduate qualification in social work supervision, although this is noted as a 'desirable' attribute in the national Field Education Guidelines (ANZASW 2016). Most schools of social work do provide short informal courses in supervision training for field instructors although attendance is voluntary. The Guidelines for Field Education (ANZASW 2016) were recently developed by the Aotearoa New Zealand Association of Social Workers (ANZASW) in collaboration with the field education sub-group of the Council of Social Work Educators Aotearoa New Zealand (CSWEANZ). These guidelines outline clear expectations for field instructors, their agencies, and higher educational institutions to strengthen the accountability and professionalism of field education in New Zealand. The limitations of the guidelines are that they are simply 'guidelines', and not enforceable as a benchmark for best practice in field education. Together with the SWRB program recognition standards (SWRB 2017) these guidelines constitute a set of expectations for social work field instruction in New Zealand.

\section{Literature}

Certainly the dynamic nature of day-to-day events that occur in placement organizations, the diversity of people students encounter and the unique and unpredictable nature of the way professional practice unfolds are all conditions that contribute to a rich learning context for students. Within this context students learn from the experiences encountered in the field, making sense of these experiences through the integration of prior knowledge, and the interaction with others such as their field instructor, clients, organizational staff and peers. This type of learning reflects a constructivist paradigm where new ways of thinking develop from being confronted with practical contextual problems, having opportunity to critically reflect and actively interpret these events with others, giving rise to new ways of knowing (Pelech 2010). This process reflects the constructivist principle that knowledge is generated from exposure to new situations with learning evolving from experience and the re-examination of prior knowledge (Pelech 2010). Students on placement encounter new experiences almost daily, signalling the importance of having accessible quality supervision to help make sense of these new and often demanding situations. This process is central for students to develop practice efficacy, a social work identity and understanding of complex client and organizational dynamics. While a constructivist paradigm posits that new learning can be derived from new experiences and social encounters, student supervision is the site where professional meaning-making of these context specific encounters can most readily occur.

The centrality of field education as a core component for learning in social work is undisputed, with prominent researchers attesting to the abiding significance of placement learning for the development of a social work professional (Bogo 2015; Kadushin 1991). Despite agreement about the integral role of field education in shaping the knowledge and skills for becoming a social worker, agency settings provide contested and variable sites for learning (Maidment 2001). To establish a foundation for field education within this contested terrain, four educational principles have been proposed that can be applied across all agency contexts (Bogo 2010, 2015). These include:

(1) field education takes place within an available and supportive relationship; (2) learners benefit from a balance between structure and autonomy in practice and learning; (3) learners need to develop reflective and conceptual capacities; and (4) observation, reflective discussion, and provision of constructive feedback facilitates mastery of skills (Bogo 2010, p. 105).

The field instructor is crucial in the application of the above principles in setting the tone and promoting the conditions within the agency setting to encourage such learning to take place. It is evident that many field instructors are aware of their responsibilities in this regard and in some cases actively seek to protect students from negative staff attitudes and practices that could impact on their learning (Chilvers 2018).

It is clear from research with social work students in field placements that they commonly experience a range of stressors (Collins et al. 2010; Litvack et al. 2010). During placement, students are likely to encounter complex and demanding situations that can be emotionally taxing such as working with children and adults who have been abused, witnessing high levels of anger or emotional distress, or potentially being threatened by a client (Grant et al. 2014). In these situations it is imperative that students have available to them supervision which is both accessible and supportive, where there is opportunity to safely reflect and request assistance and instruction where necessary (Davys and Beddoe 2009). Student supervision is a space where immediate attention can be offered to develop the level of emotional resilience 
necessary for the exigencies of practice (Kanno and Koeske 2010). Grant, Kinman, and Baker (2015) found that input from field instructors is key to helping students generate self-awareness, develop strategies for building resilience and increase capacity for reflective practice to address the stressors encountered in day-to-day social work. These findings are in keeping with earlier assertions that note that field instructors are not only tasked with reporting on student learning and development but also have a responsibility to prepare students in ways to address potential professional burnout and compassion fatigue (Bride and Figley 2007).

Research with placement students indicates that the nature of the relationship between the student and their field instructor is a crucial risk or protective factor for student wellbeing and learning (Litvack et al. 2010). Significantly, social work students who work with difficult clients and do not receive adequate supervision or instruction risk experiencing work-related emotional burnout, while those that do have access to quality supervision (including positive feedback processes) feel more empowered by practice challenges, engendering a sense of satisfaction, confidence and efficacy within their fieldwork (Kanno and Koeske 2010).

The organizational environment in which the placement occurs can either enhance or hinder student learning (Agglias 2010; Litvack et al. 2010). These authors found that in organizations where difficult power dynamics or stressful events occurred these could be mitigated and used as teaching moments in cases where the student had a good relationship with their field instructor. Where such a relationship did not exist, the negative organizational context combined with a poor supervisory relationship resulted in a "toxic situation" that impacted negatively on student learning (Litvack et al. 2010, p. 234). Establishing trust between the student and their field instructor is crucial for an effective and safe supervisory relationship to exist (Egan et al. 2017).

Research into field education indicates that social work students undertake placements in a diverse range of organizational settings (Hay et al. 2014). Accessing enough field placements to allocate to students is a well-worn subject in the social work literature within a climate of placement shortage and agency saturation (Ayala et al. 2018; Hay et al. 2014). Striking the balance between finding enough placements while also being mindful of the 'quality' in terms of organizational setting and availability of student supervision is at the heart of the allocation agenda (Gordon et al. 2009). Importantly, negotiations for field placements occur within a context where there is often urgency from both the academic institution and students to get the field education component of the social work degree completed in a timely fashion.

Previous research conducted with students on field placements in New Zealand has identified the notion of 'luck', as being part of the student discourse when discussing their field placements (Maidment 2001; Moorhouse et al. 2014).
Philosophers theorising luck refer to this concept using three types of conditions: chance conditions; lack of control conditions; and significance conditions (Broncano-Berrocal 2015). This author argues that the notion of luck signifies a lack of control over the relevant event, in this case the field placement allocation and supervision received. Adopting this discourse appears to suggest that students believe their placement allocation and subsequent supervision experience is not so much a planned process but one left to chance where they may be 'lucky' or not with the field instructor and organization to which they are allocated. This discourse hints at a sense of powerlessness and lack of agency students feel related to placement allocation.

Research to gather the views of students and program faculty in New Zealand about their perceptions of placement supervision is minimal (Maidment 2001; Moorhouse et al. 2014) with most studies focusing more on managers' and field instructors' perspectives (Chilvers 2018; Hay and Brown 2015; Hay et al. 2016). Better understanding of program faculty and student views on the supervision curriculum and experiences of supervision during placement may contribute to future curriculum developments and thus enhance graduate readiness to practise, the broader focus of our research. This article reports on one aspect of the focus groups undertaken with program faculty members and final year students, that is, the curriculum and experiences of placement supervision.

\section{Method}

\section{Larger Study Design}

The 3-year study on enhancing the readiness to practise of newly qualified social workers employed a mixed-methods approach. The first phase had a primary emphasis on the planned, delivered and experienced social work curriculum (Harden 2001). A process of curriculum mapping was firstly applied to the course descriptors from the fourteen (14) social work schools that agreed to participate in the project. Curriculum mapping is an established methodological approach that enables a visual representation of the declared curriculum (Ervin et al. 2013). While mapping alternative curricula allows comparisons and patterns to become visible, schools were likely to use different terms to express educational topics and concepts. Therefore, a taxonomy of standard vocabulary across the different curricula was created (Ballantyne et al. 2016). The taxonomy and database provide a snapshot in time of the planned curriculum for social work in New Zealand. Focus groups with program faculty and students were then used as the method to collect data for the purpose of exploring the taught and learned curriculum. 


\section{Ethics}

Ethics approval was granted by the [Name of institutional Ethics Committee]. Ethical considerations focused on confidentiality of the participating schools as well as the focus group participants. The potential for conflicts of interest was addressed by the focus group interviews not being conducted by researchers from that participating institution. The interviews were then transcribed by the research assistant and de-identified by the researcher before being shared with the research team. Participants were fully informed about the purpose of the research, their rights, and the storage and use of data in the information sheet and verbally prior to the interviews. Informed consent was obtained from all individual participants included in the study.

\section{Research Design and Participants}

There are 17 institutions offering programs recognized by the SWRB in New Zealand. Since some institutions offer more than one recognized program (a Bachelor of Social Work (BSW) and a Master of Applied Social Work (MASW) for example), there are a total of 22 social work programs. At the beginning of the project a letter inviting each school of social work to participate in the research was sent to the 17 Heads of School. Fourteen (82\%) of the schools agreed to participate in the study, and between them they offered $19(86 \%)$ of all recognized programs. Of the 19 programs included in the study, 14 were Bachelor's Degree programs, two were Bachelor Honours Degree programs, and three were Master's Degree programs.

Following the curriculum mapping exercise described above, the researchers approached the Heads of School from the participating institutions for permission to email senior students and program faculty with information about participating in focus groups. Eight institutions responded favourably to this request and a liaison was established between the school administrator and the research assistant to determine a convenient time for the focus groups. The eight schools were geographically spread throughout New Zealand, and included both polytechnics and universities. The information sheet, interview schedule, consent form and focus group details were also distributed by the administrator to potential participants. At this point potential participants could then make direct contact with the research assistant, thus ensuring confidentiality from the program head and other staff or students.

The interviews and focus groups were conducted at the participating institution by a researcher not employed by the school. Due to timing and availability, some students and one faculty member were interviewed by telephone or Skype. This meant that seven focus groups and five individual interviews were held with students, and eight focus groups and two individual interviews with faculty members. The interviews were audio-recorded and were 60-90 $\mathrm{min}$ in duration. Consent forms were signed prior to the interview. A semi-structured interview format was followed; consideration of the literature informed the interview schedule; and feedback from a recent graduate and a social work academic further ensured the suitability of the questions. All of the authors facilitated interviews, which was helpful for practical reasons, however this also meant that the questions and interview structure were not entirely consistent.

In total, 27 faculty members and 35 students engaged in the focus groups during the period between November 2016 and February 2017. The faculty members ranged from being new to academia to having over 3 decades in higher education. The program faculty taught across a range of subjects, mostly in the BSW. Nine taught in qualifying master's programs. The majority of the students were in fulltime study and all but two were enrolled in a BSW. Most of the students were completing the 3rd or 4th year of the Bachelor's program or the final year of the qualifying master's degree.

\section{Analysis}

The data was analysed using a thematic approach, initially driven by the interview questions (Bryman 2012). As one method used to increase credibility and trustworthiness, the transcripts were de-identified by the interviewer prior to them being coded by one researcher using NVivo 11. A codebook highlighted the overarching nodes and the node reports were then analysed by two different researchers who identified themes for the thematic tables. These researchers discussed similarities and differences in the identified themes and rechecked the nodes if necessary to determine the final themes. The program faculty and student data were analysed separately and then integrated following the completion of the thematic tables. Using three researchers in the coding process helped ensure credibility of the findings. As the research involved an in-depth study of a relatively small number of participants from a specific context, it cannot be claimed that the results can be transferred to other contexts. However, the researchers have endeavoured to produce a thick description of the perceptions of the participants, thus enabling readers to draw their own conclusions regarding the transferability of the results to other contexts and times (Bryman 2012; Shenton 2004).

All demographic data is reported in this article in a manner that assures anonymity. Quotations from individual participants are not attributed to them or their institution and an alphanumeric code or the neutral pronoun 'they' is used to further guarantee anonymity. The descriptors below (for example, Student FG [Focus Group] A) indicates a particular focus group rather than an individual student. Faculty and student codes are not aligned (for example, Student A is not 
necessarily from the same participating institution as Faculty A), thus further protecting anonymity.

\section{Findings}

The data from the student and program faculty focus groups illustrated the centrality of the field placement and supervision for cementing previous learning and enhancing the preparedness of students for their social work career. Several themes were generated from the data and are discussed below. The program faculty and students questioned the adequacy of the current supervision curriculum and the associated classroom teaching. The participants also highlighted the effects of current underfunding in social work field education. The accessibility of supervision during placements was another notable theme. A strong discourse of luck was evident throughout the student responses, suggesting that they feel limited control over placement allocation and placement supervision.

\section{The Supervision Curriculum}

Supervision is a subject taught in all of the social work programs in New Zealand although some students questioned whether the classroom teaching was useful:

They did spend a lot of time trying to explain supervision but... but what the hell is it? You don't know it until you're actually getting it and then you don't know if you're getting it right (Student FG I).

These students recommended having the opportunity to experience supervision on campus, prior to placement as "having any experience in supervision before you actually go in to, on placement, would actually give you an idea of what supervision is supposed to be, so you would know whether you're missing it or not" (Student FG I). Interestingly, the program faculty also wondered about the adequacy of the teaching content related to supervision:

We introduce supervision as a concept, they get supervision while they're on practice, we talk about how important it is ... but do we do enough that says what is your role in supervision, what is their role in supervision, what are the different types of supervision? (Faculty FG A).

Field instructors are not required to complete any specific training prior to student placements and this was highlighted by students as potentially affecting the quality of supervision:

I wonder how prepared the supervisors are for us and I wonder about their supervision qualifications because, trust me, it seems like nothing. Supervision was taking the cases that you were working on into the room and talking about those, that was what my supervisor thought supervision was. It wasn't deep reflection on what was going on and I wonder whether the supervisors need to have a day's worth of training on [supervision] (Student FG A).

Underfunding of social work programs was repeatedly identified by program faculty as a significant barrier for the preparation and teaching of both social work students and field instructors and as the students identify below, lack of funding also affects agency willingness to take placement students:

We are underfunded, we don't have enough staff to teach in the way that we need to teach and that is particularly around fieldwork education. We can't support our field [instructors] to learn as much as we want them to. We can't support them financially (Faculty FG D).

...agencies who do placements get zero money, it's a mess compared to other countries that do get a kind of payment, they vie to get students on placement (Student FG A).

\section{Accessing Quality Supervision}

Weekly supervision (or equivalent) is a mandated requirement for all placement students in New Zealand (SWRB 2017). Unfortunately, being unable to access regular supervision on placement was a common thread in the student focus groups:

On my third year that was an absolute disaster and it [supervision] didn't happen for six, seven weeks ... (Student FG J).

I had only eight out of my twenty-three weeks I had supervision... when you're meant to have it weekly (Student FG A).

Regular, quality supervision appeared to some students as more difficult to access in statutory sector placements; attributed to high workloads "because they are incredibly busy, they are really busy" (Student FG C). Irregular placement supervision was also aligned with unsafe practice:

...in our cohort there was at least four people who...oh there was more than that who didn't have any supervision...one didn't have supervision their whole placement and ended up having quite a meltdown ... it was just really unsafe practice (Student FG A).

The emphasis on case management rather than a reflexive supervision style, also associated with the statutory 
organizations, raised further questions from students as to the adequacy of some supervision practice:

My first supervision session [with a RSW in a statutory agency] started off by saying, she asked me what I expected from it and I said, supervision and I want to tie it to theory and she said, oh I'm not actually a reflective person, I just do the job (Student FG J).

The high levels of employment for students following their placements was often proudly referred to in the faculty focus groups and was seen as indicative of student readiness to practise. From the student perspective however, decisions around future employment were primarily influenced by the regularity and quality of supervision on their placement; signalling student agency in the employment process:

The supervisor is really supportive. Yeah, they offer me like a weekly internal supervision, fortnightly supervision, fortnightly peer supervision. ... so yeah I prefer I would work for NGO [non-government organization] as my first job (Student FG C).

I think right now if you ask me to do that kind of job I can't do that ... it's not good for a new social worker because they don't provide formal or regular supervision (Student FG C).

Current resource constraints in New Zealand mean that not all students have external supervision available to them, although both faculty staff and students valued the provision of this type of supervision as a way of ensuring all students had access to quality, regular supervision.

I feel somehow like the [educational institution] needs to have an external [field instructor] who's accredited $\ldots$ and make sure that it occurs because when you're out in an agency it's not occurring just because of the nature of the work and how busy it is (Student FG J). I mean those students who have external supervision with us they benefit and they are really advantaged. They are in social work placements without a social worker and so we provide supervision for them and they have that continuous catch up with each other with a good social work supervisor (Faculty FG C).

This emphasis on external supervision raises questions concerning the efficacy of current individual supervision models and organizational commitment to allowing field instructors sufficient time to supervise student placements.

\section{Luck}

Repeated references to the concept of luck and similar sentiments were evident within the student focus group discussions. Referring to oneself as lucky suggests that students view field instructor selection as one based on chance rather than a planned process. In the quote below this student claims she is 'fortunate' and 'lucky' to have a good field instructor who helped build critical thinking capacity:

I was so fortunate in my first placement to have a supervisor who encouraged and nurtured critical thinking. I was so lucky, I didn't realise how lucky I was and then to be thrown into [statutory placement agency] this year where critical thinking is like this incredibly rare thing (Student FG A).

Reference to being 'thrown' into the statutory placement does not speak to a careful allocation process, which program faculty signalled was their approach to organising placements. Hence, there is a disjuncture between how higher educational institutions discuss planned placement allocation with the sense of randomness in the way students express their experience of allocations. Students 'feel lucky' if they get a good placement agency and access to quality supervision. Similarly, a student from a different institution noted she was 'lucky' to have such rich learning transactions:

I've been really lucky on my two placements, I've had really good supervision, so much so that they keep on asking me all these questions about theory and reflective .. and I'm like, oh my god, I have to think .. so it's quite a different experience [from peers] but I know that I've been quite lucky and it [supervision] was pretty much weekly (Student FG J).

In keeping with a constructivist paradigm one of the student focus groups discussed the peer learning and support derived from discussions between students but attributed this process to luck rather than an educational strategy used for learning.

I'd say that we are a really lucky class, our particular year are really good conversationalists and communicators and supportive of each other so we're really lucky to have opened [up] these conversations with each other as well, which piqued interests and keeps us informed. (Student FG I)

Certainly students who had opportunities while on placement to connect with peers and discuss what was happening for them derived significant support from this process. The organizational culture and openness to having a student on placement is critical for effective learning but was also seen to be somewhat rare and outside of the norm:

I've been very fortunate with my agency, you know, they've really got me out there doing the job ... and I think I've just been quite fortunate that I've walked into this agency very open to have a student that really [provides] hands-on experience and challenges me not 
to a point where I'm broken down and can't do it, but again if I do struggle I ask for help (Student FG H).

\section{Discussion}

Several interesting features have come to the fore in the analysis of data from this research. One of the key messages we received was that students attributed receiving good supervision, experiencing peer learning and engaging with functional social service organizations as a matter of good luck, rather than being exposed to planned learning opportunities. Without doubt, supervision has a critical role in the professional development of students while they are on placement (Bogo and McKnight 2006). In keeping with the principles for quality field instruction discussed earlier (Bogo 2010), accessible supervision that helps grow reflective capacity and conceptual thinking with opportunities to engage with constructivist learning through discussions with the field instructor and peers is optimal. The findings from this study demonstrate that while placement supervision was identified as important by both program faculty members and students, there were significant gaps between what is espoused by higher educational institutions and what is experienced by students on placements.

Insufficient supervision is not a new issue with previous research indicating that it may lead to students being more vulnerable in the placement environment or risking burnout (Kanno and Koeske 2010). While students in challenging placements may be able to cope if they are receiving timely, helpful supervision, if it is largely absent then this can be debilitating (Litvack et al. 2010). In pressured environments, as highlighted by several student comments, supervision can often become focused on tasks and managing risk, which limits opportunities to reflect and consider the integration of theory and practice (Chinnery and Beddoe 2011). Poor supervision on placement is likely to reflect the standard of supervision practice in that organization, which not only affects students' development but also retention and safe practice once in employment (Zeira and Schiff 2014). The students participating in this research recognized this relationship between supervision, staff retention and safe practice.

The social work curriculum in New Zealand includes the teaching of knowledge and skills on supervision (Ballantyne et al. 2016). There is a tension, however, between what is taught in the degree programs and what students experience on placement. An understanding of supervision styles and how to build an effective supervisor-supervisee relationship based on trust gives students courage to advocate for better supervision, if necessary, while on placement (Egan et al. 2017). A strong supervisory relationship can also mitigate the multiple stressors experienced by students on placement, thus strengthening their professional practice and identity (Grant et al. 2014).

The nature of the environment and culture of the organization hosting the student has considerable bearing on the success or otherwise of the placement trajectory (Litvack et al. 2010). As Dunn et al. (2016) propose, a successful match between a student's skills, knowledge and values,nd the field instructor and their organizational setting is vital for ensuring the effectiveness of the placement. Sourcing suitable placements is often challenging for program faculty and the matching process may be somewhat haphazard. This can result in limited attention being paid to whether individual students are suited for the specific agency and type of work on offer (Hay et al. 2014). Despite this, students engaged in challenging work environments can build practice capacity and manage the demands when an encouraging supervisor who supports reflective practice is accessible (Agllias 2010; Kanno and Koeske 2010).

In contrast to some of the findings in this study, previous research has highlighted that students generally prefer their primary supervisory relationship to be in the placement organization (Cleak and Smith 2012). External field instructors are not available to students on a daily basis and generally have limited insight into the placement organization (Zuchowski 2013). That said, external supervisors can provide a safe, objective space for new learning to students (Zuchowski 2013). Whether supervision is provided internally or externally, field instructors and students need to be given the time and resourcing to develop safe relationships as well as engage in regular sessions (Beddoe 2012).

Congruent with other research findings from the New Zealand context (Maidment 2001; Moorhouse et al. 2014), students felt lucky to be on a placement in an organization where they could experience relevant learning both within the organizational context and in supervision, compared to their peers who were not so lucky. The variability of quality in relation to organizational learning settings and the provision of supervision, raised by many students in this study, is a significant concern.

\section{Limitations}

There are some limitations to our study. As with most qualitative studies, the findings provide only a snapshot in place and time, in this instance, an aspect of social work education in New Zealand in the 2016-2017 period. Further, we depended on people's subjective perspectives on supervision and field education and the decision by other faculty staff and students not to participate in the study may result in bias. The dynamics of focus groups also means that we cannot be sure we captured the full extent of each interviewee's knowledge or experiences. The inclusion of larger numbers 
of participants and more schools of social work would have provided greater diversity.

\section{Implications}

Our findings signal a number of issues relevant for program faculty and field instructors wishing to increase the quality experiences of supervision, and field education more generally, for placement students.

First, given the variability in the student experiences of placement allocation, program faculty should consider how to strengthen their relationships with both students and field instructors to support the allocation process (Gordon et al. 2009). This might require additional workload provision and resourcing for faculty members to enable the time to build these networks with potential field instructors and other placement agency staff. A national conversation with faculty, employers, field instructors, the SWRB and ANZASW to clarify student supervision expectations and standards could lead to better quality supervision for students. This would build on the previous development of the national Field Education Guidelines (ANZASW 2016) and is a planned strategy as part of the final phase of this current research.

Second, students could increase their knowledge and supervision experience prior to their placements through improvements in campus teaching and the scaffolding of learning throughout the degree curriculum. Opportunities for students to access supervision through the higher educational institution while they are studying other courses would allow for valuable experiential learning prior to placement.

Third, field instructor knowledge of supervisory roles and responsibilities, as outlined in the national Field Education Guidelines, needs embedding in both student and field instructor curriculum and training so that supervision is fully realised as a protective factor for students (ANZASW 2016; Litvack et al. 2010). Establishing accessible and consistent nation-wide training of models of supervision that are relevant to different practice contexts (Davys and Beddoe 2009), would benefit all social work students and increase the quality of supervision provision.

Fourth, it is imperative that the SWRB requirement of regular (weekly or equivalent) access to supervision is upheld on student placements (SWRB 2017). A threepronged approach to addressing this concern is recommended. Firstly, interviewing field instructors and agencies to find out why they are not offering the components in quality supervision and why in so many instances students are not receiving the most basic allotment of time for supervision is pertinent. Secondly, lobbying for increased funding for the higher educational providers could enable them to have greater flexibility in how they support organizations as well as individual field instructors. Discussions regarding the funding band for social work education are currently in progress with the Tertiary Education Commission in New Zealand. Thirdly, additional resources could then incentivise involvement in field education, as managers could relieve some of the workload pressures on field instructors so they have more time available to support and supervise students. If internal supervision is being provided regularly and in an effective manner then the desire for external supervision, unless necessary due to constraints around the availability of a registered social worker, may also decrease.

Finally, by implementing these recommendations the educational principles that underpin effective field education can be more fully realised in New Zealand (Bogo 2010). The strong notion of luck that has been evident from students in this study may then be replaced by the expectation and reality that all students can, and should, receive quality supervision during a learning-focused placement.

Funding This project was funded by a National Project Grant, Ako Aotearoa.

\section{Compliance with Ethical Standards}

Ethical Approval All procedures performed in studies involving human participants were in accordance with the ethical standards of the institutional and/or national research committee and with the 1964 Helsinki Declaration and its later amendments or comparable ethical standards.

\section{References}

Agllias, K. (2010). Student to practitioner: A study of preparedness for social work practice. Australian Social Work, 63(3), 345-360.

ANZASW. (2016). Guidelines for Field Education. Retrieved from https://anzasw.nz/wp-content/uploads/ANZASW-Social-WorkField-Education-Guidelines.pdf.

Ayala, J., Drolet, J., Fulton, A., Hewson, J., Letkemann, L., Baynton, M., \& Schweizer, E. (2018). Field education in crisis: Experiences of field education coordinators in Canada. Social Work Education, 37(3), 281-293.

Ballantyne, N., Beddoe, L., Hay, K., Maidment, J., Ngan, L., \& Walker, S. (2016). Technical report three: TISWEANZ taxonomy. Retrieved from https://akoaotearoa.ac.nz/node/12658/files/.

Beddoe, L. (2012). External supervision in social work: Power, space, risk, and the search for safety. Australian Social Work, 65(2), 197-213. https://doi.org/10.1080/0312407X.2011.591187.

Bennett, P. (2014). Speech at the 'Protecting the Public-Enhancing the Profession' conference, Social Workers Registration Board, Wellington, NZ.

Bogo, M. (2010). Achieving competence in social work through field education. Toronto: University of Toronto Press.

Bogo, M. (2015). Field education for clinical social work practice: Best practices and contemporary challenges. Clinical Social Work Journal, 43(3), 317-324.

Bogo, M., \& McKnight, K. (2006). Clinical supervision in social work. The Clinical Supervisor, 24(1-2), 49-67. https://doi.org/10.1300/ J001v24n01_04. 
Bride, B., \& Figley, C. (2007). The fatigue of compassionate social workers. An introduction to the special edition on compassion fatigue. Clinical Social Work Journal, 35, 151-153.

Broncano-Berrocal, F. (2015). Luck as risk and the lack of control account of luck. In D. Pritchard \& L. Whittington (Eds.), The philosophy of luck (pp. 3-26). Chichester: Wiley.

Bryman, A. (2012). Social research methods (4th edn.). Oxford: Oxford University Press.

Chilvers, D. (2018). Social work field educator practice: Expanding the vision. (Unpublished PhD Thesis). University of Canterbury, Christchurch, New Zealand.

Chinnery, S. A., \& Beddoe, L. (2011). Taking active steps towards the competent use of self in social work. Advances in Social Work and Welfare Education, 13(1), 89-106.

Cleak, H., \& Smith, D. (2012). Student satisfaction with models of field placement supervision. Australian Social Work, 65(2), 243-258. https://doi.org/10.1080/0312407x.2011.572981.

Collins, S., Coffey, M., \& Morris, L. (2010). Social work students, stress, support and wellbeing. British Journal of Social Work, 40(3), 963-982. https://doi.org/10.1093/bjsw/bcn148.

Davys, A. M., \& Beddoe, L. (2009). The reflective learning model: Supervision of social work students. Social Work Education, 28(8), 919-933. https://doi.org/10.1080/02615470902748662.

Dunn, L. A., Schier, M. A., Hiller, J. E., \& Harding, I. H. (2016). Eligibility requirements for work-integrated learning programs: Exploring the implications of using grade point averages for student participation. Asia-Pacific Journal of Cooperative Education, 17(3), 298-308

Egan, R., Maidment, J., \& Connolly, M. (2017). Trust, power and safety in the social work supervisory relationship: Results from Australian research. Journal of Social Work Practice, 31(3), 307-321.

Ervin, L., Carter, B., \& Robinson, P. (2013). Curriculum mapping: Not as straightforward as it sounds. Journal of Vocational Education and Training, 65(3), 309-318.

Gordon, J., McGeoch, M., \& Stewart, A. (2009). Finding the way forward: Planning for practice learning in West of Scotland. Journal of Practice Teaching and Learning, 9(1), 46-63.

Grant, L., Kinman, G., \& Alexander, K. (2014). What's all this talk about emotion? Developing emotional intelligence in social work students. Social Work Education, 33(7), 874-889.

Grant, L., Kinman, G., \& Baker, S. (2015). 'Put on your own oxygen mask before assisting others': Social work educators' perspectives on an 'emotional curriculum'. The British Journal of Social Work, 45(8), 2351-2367.

Harden, R. M. (2001). AMEE Guide No. 21: Curriculum mapping: A tool for transparent and authentic teaching and learning. Medical Teacher, 23(2), 123-137. https://doi.org/10.1080/0142159012 0036547.

Hay, K., Ballantyne, N., \& Brown, K. (2014). Hic sunt dracones: Here be dragons! Difficulties mapping the demand for social work placements in New Zealand. Journal of Practice Teaching and Learning, 13(1), 24-43.

Hay, K., \& Brown, K. (2015). Social work practice placements in Aotearoa New Zealand: Agency managers' perspectives. Social Work Education, 34(6), 700-715.
Hay, K., Dale, M., \& Yeung, P. (2016). Influencing the future generation of social workers: Field educator perspectives on social work field education. Advances in Social Work and Welfare Education, 18(1), 39-54.

Kadushin, A. (1991). Introduction. In D. Schneck, B. Grossman \& U. Glassman (Eds.), Field education in social work: Contemporary issue and trends (pp. 11-12). Dubuque: Kendall/Hunt.

Kanno, H., \& Koeske, G. (2010). MSW students' satisfaction with their field placements: The role of preparedness and supervision quality. Journal of Social Work Supervision, 46(1), 23-38.

Litvack, A., Bogo, M., \& Mishna, F. (2010). Emotional reactions of students in field education: An exploratory study. Journal of Social Work Education, 46(2), 227-243.

Maidment, J. (2001). Teaching and learning social work in the field: Student and field educator experiences.. Social Work Review, 13(2), 2-6.

Moorhouse, L., Hay, K., \& O'Donoghue, K. (2014). Listening to student experiences of supervision. Aotearoa New Zealand Social Work, 26(4), 37-51.

Pelech, J. (2010). The comprehensive handbook of constructivist teaching. Charlotte: Information Age Publishing.

Radio New Zealand. (2015). What needs to change at Child Youth \& Family? Interview with Russell Wills, Commissioner for Children.

Shenton, A. K. (2004). Strategies for ensuring trustworthiness in qualitative research projects. Education for Information, 22(2), 63-75.

SWRB. (2017). Program Recognition Standards. Retrieved from http:// swrb.govt.nz/about-us/policies/.

Zeira, A., \& Schiff, M. (2014). Field education: A comparison of students' and novice social workers' perspectives. British Journal of Social Work, 44(7), 1950-1966. https://doi.org/10.1093/bjsw/ bct038.

Zuchowski, I. (2013). From being 'caught in the middle of a war' to being 'in a really safe space'- social work field education with external supervision. Advances in Social Work and Welfare Education, 15(1), 105-120.

Kathryn Hay is a Senior Lecturer in the School of Social Work at Massey University, Palmerston North, New Zealand.

Jane Maidment is a Professor of Social Workin the Human Services and Social Work Department at the University of Canterbury, Christchurch, New Zealand.

Neil Ballantyne is a Senior Lecturer in the School of Health and Social Sciences at the Open Polytechnic, Wellington, New Zealand.

Liz Beddoe is Associate Professor in the School of Counselling, Human Services and Social Work University of Auckland, Auckland, New Zealand.

Shayne Walker is a Senior Lecturer in the Department of Sociology, Gender \& Social Work at Otago University, Dunedin, New Zealand. 